\title{
A Case of Squamous Cell Carcinoma in the External Auditory Canal Previously Treated for Verrucous Carcinoma
}

\author{
Soo Jung Nam, Chan Joo Yang, and Jong Woo Chung \\ Department of Otolaryngology, Asan Medical Center, University of Ulsan College of Medicine, Seoul, Korea
}

\author{
Received October 10,2016 \\ Revised November 2, 2016 \\ Accepted November 6, 2016 \\ Address for correspondence \\ Jong Woo Chung, MD, PhD \\ Department of Otolaryngology, \\ Asan Medical Center, \\ University of Ulsan \\ College of Medicine, \\ 88 Olympic-ro 43-gil, Songpa-gu, \\ Seoul 05505, Korea \\ Tel +82-2-3010-3718 \\ Fax +82-2-489-2773 \\ E-mail jwchung@amc.seoul.kr
}

\begin{abstract}
Carcinoma in the external auditory canal (EAC) is a rare malignancy with an annual incidence of one per one million people, accounting for less than $0.2 \%$ of all head and neck cancers. The most common histopathological type of EAC cancer is squamous cell carcinoma. Verrucous carcinoma is a well-differentiated, low-grade variant of squamous cell carcinoma. It is a locally destructive, invasive, and slow growing tumor that rarely metastasizes. Verrucous carcinoma occurs predominantly in the oral cavity and larynx, and its occurrence in the EAC is extremely rare. In this report, we present a histologically confirmed case of verrucous carcinoma in the EAC and temporal bone, which for several years had been classified as epithelial hyperplasia. Two-and-a-half years after diagnosis of verrucous carcinoma, a recurrent mass was found and the lesion was then confirmed to be squamous cell carcinoma.

J Audiol Otol 2016;20(3):183-186
\end{abstract}

KEY WORDS: Ear canal · Verrucous carcinoma - Squamous cell carcinoma $\cdot$ Temporal bone.

\section{Introduction}

The occurrence of carcinoma in the external auditory canal (EAC) is rare, with an annual incidence of one per one million people, accounting for less than $0.2 \%$ of all head and neck cancers $[1,2]$. The most common histological type of carcinoma in the EAC is squamous cell. Verrucous carcinoma is a well-differentiated variant of squamous cell carcinoma, which is a low-grade malignancy and described as slow growing, locally destructive, and invasive, but not metastatic [3]. Verrucous carcinoma of the head and neck area occurs predominantly in the oral cavity and larynx, and less commonly in the esophagus and genital area [4]. It is extremely unusual for this cancer to occur in the EAC.

Histologically, verrucous carcinoma displays keratosis, parakeratosis, hyperkeratosis, papillomatosis, and acanthosis. The mass may infiltrate deeply with thickened squamous epithelium pushing borders but not invading the basement

This is an Open Access article distributed under the terms of the Creative Commons Attribution Non-Commercial License (http://creativecommons.org/licenses/by-nc/3.0/) which permits unrestricted non-commercial use, distribution, and reproduction in any medium, provided the original work is properly cited. membrane [5]. A biopsy of such a lesion can be mistakenly classified as benign.

We present a case of squamous cell carcinoma in the EAC occurring at a site where verrucous carcinoma had been previously treated. A slowly growing papillomatous lesion of the EAC was repeatedly confirmed by biopsies over several years, but aggravation by the growing mass eventually caused otalgia. The patient had surgery, and the mass was histologically diagnosed as verrucous carcinoma. During follow-up after surgery, a slow growing remnant mass was identified. After reviewing the specimen removed at surgery, squamous cell carcinoma was diagnosed. Here, we discuss the case and provide a brief review of the related literature.

\section{Case Report}

A 54-year-old man visited our clinic after 20 days of experiencing intermittent left hearing disturbance, and 1 week of left aural fullness and otorrhea at November 2007. He had a history of hypertension and diabetes mellitus for which he was on medication, and had received stenting for an acute myocardial infarction 2 years previously. A mass and crust 
were observed on the inferior portion of the left EAC on physical examination (Fig. 1A); the tympanic membrane looked normal. The right ear had a normal appearance. When we removed the crust on the inferior portion of the EAC, it bled easily. This left EAC mass had been identified at another hospital 1 year previously, and a biopsy performed 6 months later led to a diagnosis of hyperkeratosis. During follow-up with left ear dressings at the other hospital, the tumor in the left EAC increased in size and a new protruding mass on the inferior portion of the tympanic membrane was discovered. According to the temporal bone computed tomography (CT) and physical findings, the tumor was considered to
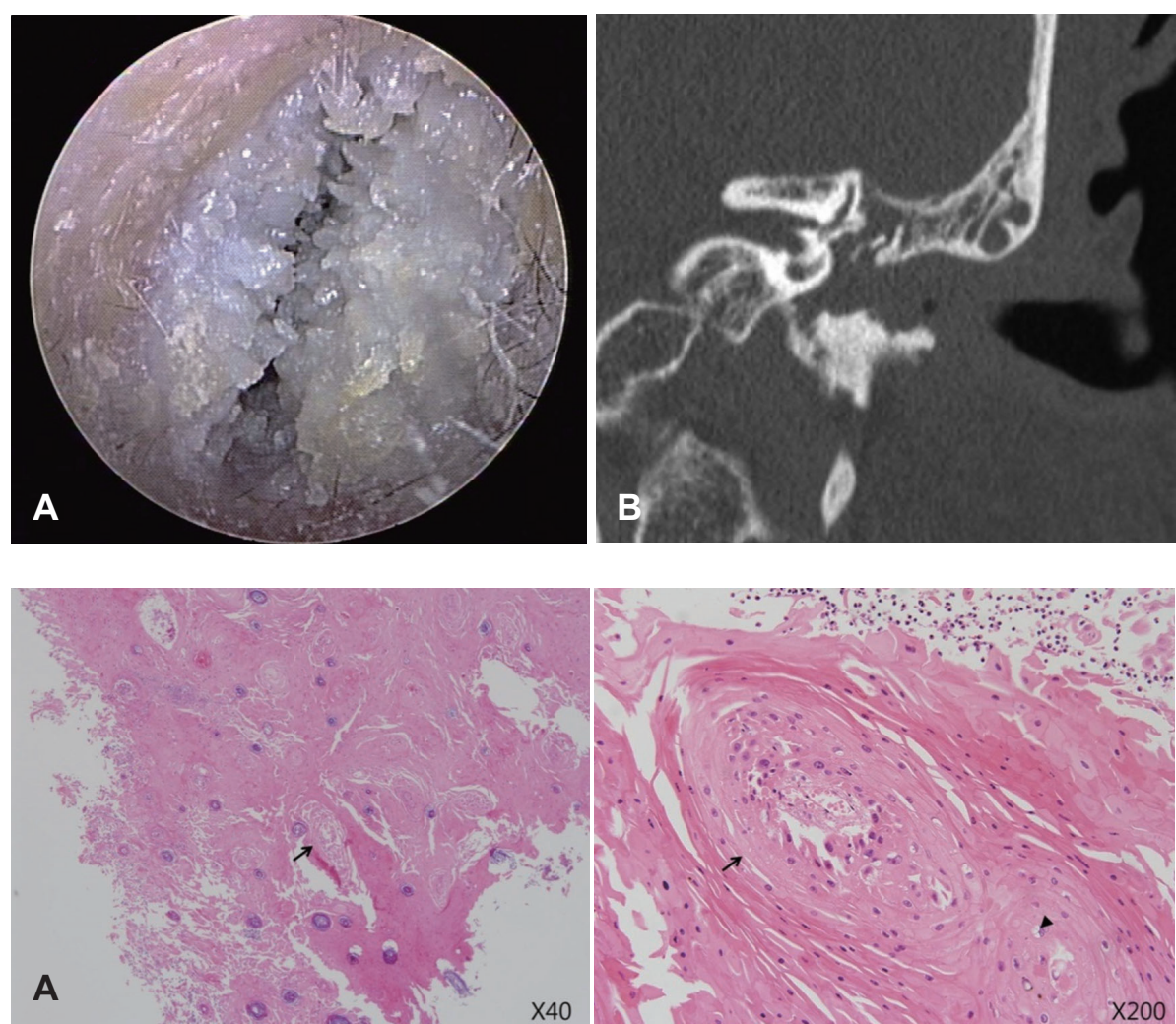

A
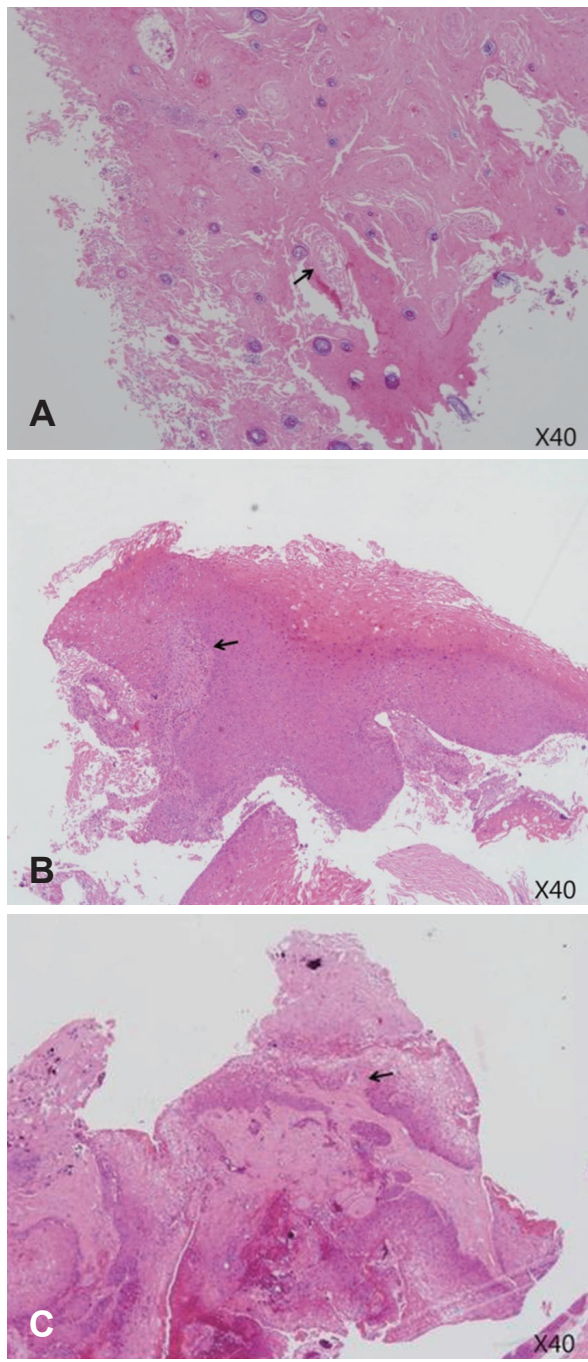
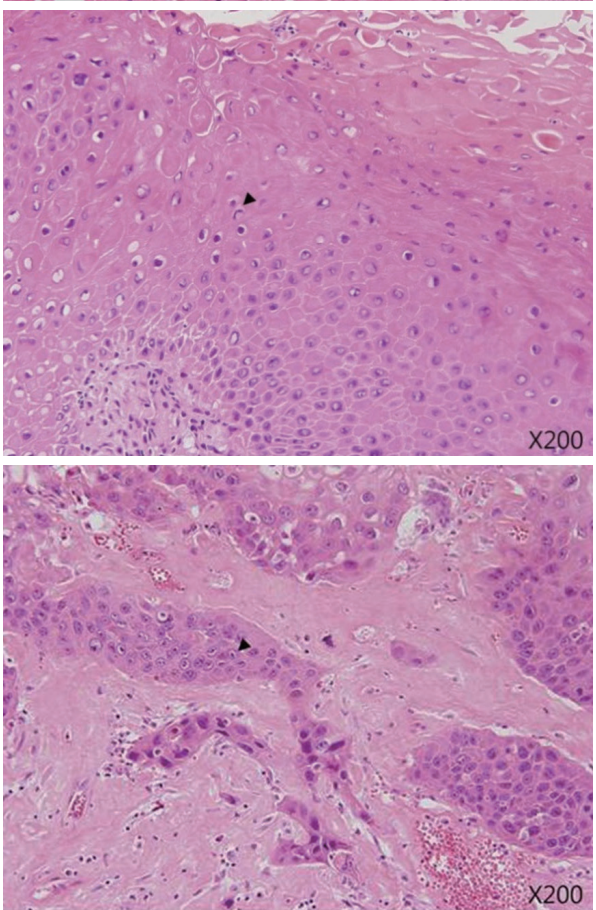

Fig. 1. A: Oto-endoscopic finding in the EAC showing keratin debris. B: Soft tissue mass in the left EAC identified by CT of the temporal bone. EAC: external auditory canal, CT: computed tomography.
Fig. 2. Pathologic findings of papillomatosis, verrucous carcinoma, and squamous cell carcinoma. A: Papillomatosis. On microscopic examination, squamous papilloma shows fibrovascular cores (arrow) covered by benign squamous epithelium and hyperkeratosis. There is no significant pleomorphism. A few koilocytes (arrowhead) are noted. B: This lesion shows elongated rete ridges (arrow) and marked hyperkeratosis at the surface viewed at low power. At high power, the squamous cells show mild cytologic atypia (arrowhead) limited to the basal zone. There is no definite stromal invasion. Overall, features are consistent with verrucous carcinoma. C: The tumor cells show mild to moderate and diffuse cytologic atypia (arrowhead). There are multiple foci of stromal invasion (arrow). 
be granulation tissue, and the patient was observed for 4 years. When he visited our clinic again because of persistent otorrhea and keratin debris in the left EAC at March 2011, CT revealed bony destruction of the inferior EAC wall (Fig. 1B). Another biopsy of the mass was performed, and the lesion was reported as papillomatosis (Fig. 2A). During treatment with local $25 \%$ podophyllin and intravenous antibiotics, the patient developed left-sided facial palsy. Because of the growth of the mass was identified in temporal bone CT and MR (Fig. 3) and aggravation of otalgia, on November 2012, excision via transotic approach was performed. Histological examination of the specimen confirmed a diagnosis of verrucous carcinoma (Fig. 2B). Postoperative follow-up by $\mathrm{CT}$ and magnetic resonance imaging revealed invasion of the clivus and Meckel's cave by carcinoma (Fig. 4). Although the patient received chemoradiotherapy, the size of the tumor increased. Thirty-one months after the transotic excision of the verrucous carcinoma, a further excision was carried out using a transcochlear approach. The frozen biopsy analysis performed during the surgery identified infiltration of cancer into the middle cranial fossa. Histological examination of the tumor confirmed squamous cell carcinoma (Fig. 2C), and the patient died with cancer 1 year later.

\section{Discussion}

Since Ackerman [6] first reported a case of verrucous car- cinoma in the oral cavity in 1948, its occurrence in the EAC was not described until 1981, by Woodson, et al. [7] according to the involved site, verrucous carcinoma is variously referred to as oral florid papillomatosis, giant condyloma of Buschke-Löwenstein, and epithelioma cuniculatum [8]. Verrucous carcinoma is a rare tumor of the head and neck, the most common sites being the oral cavity and larynx [4,5]. It very rarely involves the ear, and only 15 cases have been reported in the literature [7,9-11].

Although the etiology of verrucous carcinoma is not well defined, the human papilloma virus (HPV) is considered one of the etiological factors. Besides HPV, poor hygiene, presence of lichenoid and leucoplakic lesions, chronic irritation and inflammation, smoking, and immunodeficiency are highly associated with verrucous carcinoma of the head and neck [10]. Clinically, verrucous carcinoma is known to be a slowly progressive tumor with locally infiltrative and destructive characteristics, and rarity of distant metastasis. Radiation therapy is considered to be one method of treating verrucous carcinoma, but compared with conventional surgery it is a relatively lower local control rate [10], and therefore surgery is preferred. Verrucous carcinoma in the oral cavity at an advanced stage can present with lymph node metastasis, for which selective neck dissection should be considered [12]. With a high recurrence rate after surgery, postoperative radiation therapy is recommended for extensive verrucous carcinoma [3]. Histologically, verrucous carcino-

Fig. 3. A: In temporal bone CT, destructing soft tissue mass is found in middle cranial fossa. Tegmen tympani, cochlea, semicircular canal, EAC are destroyed. B: In T2 weighted-MR, intermediate low signal intensity lesion is extended into petrous apex. EAC: external auditory canal, CT: computed tomography.
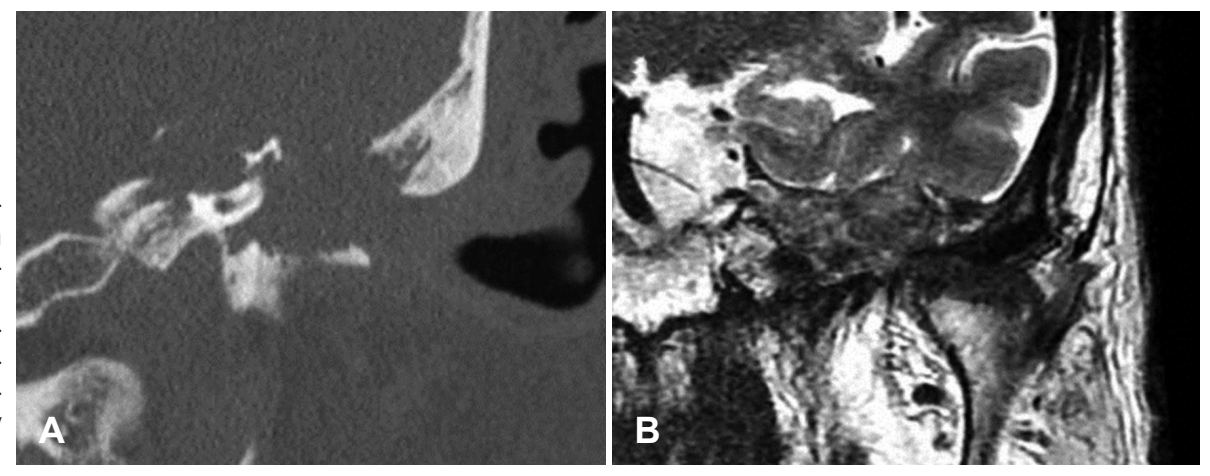

Fig. 4. A: Soft tissue is observed in postoperative site. B: In temporal bone T2 weighted-MR, heterogeneous enhancing intermediate low signal intensity lesion is observed in left petrous apex with left Meckel's cave.
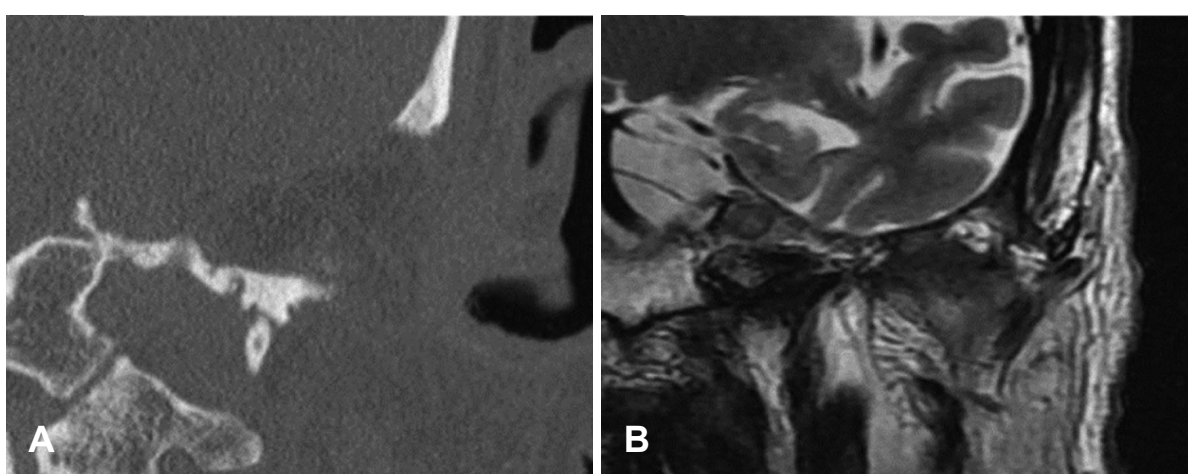
ma presents as hyperkeratosis, papillomatosis, and acanthosis in the epidermis layer, pushing the margin with broad rete pegs into the dermis [11]. Chronic inflammatory cells are infiltrated around the tumor, and, unlike squamous cell carcinoma, the basement membrane between the epidermis and the dermis appears to be intact [5]. The common wart is histologically similar to verrucous carcinoma, but it is distinguished by koilocytes, keratohyaline granules, and inward bending of rete ridges into the Malpighian layer. Sometimes, a more aggressive squamous cell carcinoma may arise in the verrucous carcinoma lesion [10]. Therefore, for differential diagnosis of verrucous carcinoma, full-thickness biopsies of the lesion are needed for histologic confirmation [13].

In this case, for 4 years each biopsy of the tumor was identified as hyperkeratosis and after that the tumor was confirmed as papillomatosis. One year later, the tumor was confirmed as verrucous carcinoma and, after a further 3 years, squamous cell carcinoma was identified.

The reason for the occurrence of squamous cell carcinoma in this patient is unknown; however, we can reasonably speculate about the pathology. First, it might be possible that squamous cell carcinoma existed concurrently with verrucous carcinoma. The resected tumor was confirmed as verrucous carcinoma, but squamous cell carcinoma could have remained. Second, transformation of the verrucous carcinoma to squamous cell is possible. Third, radiation treatment of the verrucous carcinoma could have induced squamous cell carcinoma. There are some reports of squamous cell carcinoma occurring after radiation therapy $[14,15]$.

Verrucous carcinoma shows a relatively low rate of metastasis to other organs, and surgical treatment after early diagnosis is the most effective treatment modality. If misdiagnosed as a benign lesion clinically and histologically, because of a superficial biopsy, inappropriate treatment will lead to a high recurrence rate. Therefore, any suspicion of verrucous carcinoma should be biopsied with full-thickness of the skin to enable extensive examination of the lesion, and treatment should be excision with a wide safety margin.

\section{Conflicts of interest}

The authors have no financial conflicts of interest.

\section{REFERENCES}

1) Moody SA, Hirsch BE, Myers EN. Squamous cell carcinoma of the external auditory canal: an evaluation of a staging system. Am J Otol 2000;21:582-8.

2) Kuhel WI, Hume CR, Selesnick SH. Cancer of the external auditory canal and temporal bone. Otolaryngol Clin North Am 1996;29:82752.

3) Oh JH, Lee HS, Hwang JH, Park KH. Reconstruction of the Auricular Defect After Excision of Verrucous Carcinoma. J Craniofac Surg 2016;27:e6-8.

4) Patel KR, Chernock RD, Zhang TR, Wang X, El-Mofty SK, Lewis JS Jr. Verrucous carcinomas of the head and neck, including those with associated squamous cell carcinoma, lack transcriptionally active high-risk human papillomavirus. Hum Pathol 2013;44:2385-92.

5) Miller ME, Martin N, Juillard GF, Bhuta S, Ishiyama A. Temporal bone verrucous carcinoma: outcomes and treatment controversy. Laryngoscope 2010;120 Suppl 4:S169.

6) Ackerman LV. Verrucous carcinoma of the oral cavity. Surgery 1948;23:670-8.

7) Woodson GE, Jurco S 3rd, Alford BR, McGavran MH. Verrucous carcinoma of the middle ear. Arch Otolaryngol 1981;107:63-5.

8) Rinker MH, Fenske NA, Scalf LA, Glass LF. Histologic variants of squamous cell carcinoma of the skin. Cancer Control 2001;8:354-63.

9) Aydogan LB, Ozdemir S, Gumurdula D. Verrucous carcinoma of the temporal bone. Am J Otolaryngol 2008;29:69-71.

10) Park $\mathrm{CH}$, Park YH. Verrucous carcinoma in the external auditory canal. Int Adv Otol 2011;7:122-4.

11) Rinaldo A, Devaney KO, Ferlito A. Verrucous carcinoma of the ear: an uncommon and difficult lesion. Acta Otolaryngol 2004;124:22830.

12) Walvekar RR, Chaukar DA, Deshpande MS, Pai PS, Chaturvedi P, Kakade A, et al. Verrucous carcinoma of the oral cavity: A clinical and pathological study of 101 cases. Oral Oncol 2009;45:47-51.

13) Ferlito A. Diagnosis and treatment of verrucous squamous cell carcinoma of the larynx: a critical review. Ann Otol Rhinol Laryngol 1985;94(6 Pt 1):575-9.

14) Shu MT, Lin HC, Lee JC, Chen BF. Radiation-induced squamous cell carcinoma of the external auditory canal. Otol Neurotol 2011; 32:e24-5.

15) Zhang X, Bai S, Li H, Hu H, Duan X, Chen M, et al. CT and MRI findings of radiation-induced external auditory canal carcinoma in patients with nasopharyngeal carcinoma after radiotherapy. Br J Radiol 2015;88:20140791. 